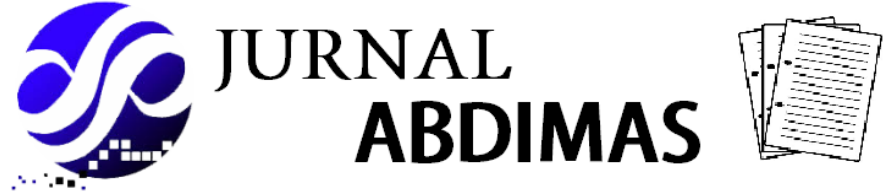

\section{Membangun Jiwa Wirausaha Kreatif (Creativepreneur) Bagi Para Pemuda Karang Taruna Banyu Urip, Surabaya}

\author{
${ }^{1}$ Moh. Ma'aruf, ${ }^{2}$ Riyan Sisiawan Putra, ${ }^{3}$ Inayatus Sholikhah, ${ }^{4}$ Ravica Ulya Arifin \\ $1,2,3,4$ Universitas Nahdlatul Ulama Surabaya
}

\begin{abstract}
Alamat Surat
Email: drmkaruf1971@gmail.com*, riyan_sisiawan@unusa.ac.id, inayatussh2@gmail.com, ravicaulya99@gmail.com
\end{abstract}

Article History:

Diajukan: 20 Januari 2021; Direvisi: 2 Februari 2021; Accepted: 5 Februari 2021

\begin{abstract}
ABSTRAK
Kegiatan pengabdian kepada masyarakat ini dilaksanakan di Balai RW Banyuurip Surabaya dan peserta kegiatan pengabdian kepada masyarakat ini dari Para pemuda karang taruna Surabaya. Pemuda karang taruna ini kurang lebihg berjumlah 50 orang. Pada era digital saat ini para pemuda mempunyai potensi besar untuk menjadi entrepreneur ataupun creativepreneur dikarenakan semakin dimudahkan dengan kecanggihan teknologi. Mengembangkan ide-ide krreatif dan menjadi pelaku usaha kreatif (creativepreneur) akan membuka berbagai peluang besar bagi kemajuan ekonomi di wilayah mereka sendiri.

Metode pelaksanaan kegiatan pengabdian kepada masyarakat ini terdiri dari tiga tahap. Pertama tahap pesiapan melalui pra-survei, pembentukan tim, pembuatan proposal, koordinasi tim dengan mitra, dan persiapan bahan untuk kegiatan bahan pengabdian kepada masyarakat. Tahap kedua yaitu tahap pelaksanaan program berupa sosialisai. Sosialisai dilakukan melalui pemaparan materi, tanya jawab dan diskusi. Dan tahap terakhi adalah pelaporan hasil kegiatan pengabdian kepadamasyarakat.
\end{abstract}

Kata kunci: Creativepreneur, Ide Bisnis, Kewirausahaan

ABSTRACT

This community service activity was carried out at the Banyuurip Surabaya $R W$ Hall and the participants of this community service activity were from the youth of Surabaya youth organization. This youth youth organization numbered approximately 50 people. In today's digital era, young people have great potential to become entrepreneurs or creativepreneurs because it is increasingly facilitated by technological sophistication. Developing creative ideas and becoming creative entrepreneurs (creativepreneurs) will open up great opportunities for economic progress in their own regions.

This method of implementing community service activities consists of three stages. The first is the preparation stage through pre-survey, team formation, proposal development, team coordination with partners, and preparation of materials for community service activities. The second stage is the program implementation stage in the form of socialization. Socialization is carried out through material presentation, question and answer and discussion. And the final stage is the reporting of the results of community service activities.

Keywords: Creativepreneur, Business Idea, Entrepreneurship

\section{PENDAHULUAN}

Pengabdian Masyarakat yang akan Tim laksanakan berlokasi di balai RW Banyuurip, Surabaya dan untuk peserta kegiatan pengabdian masyarakat ini berasal dari para pemuda karangtaruna Banyuurip, Surabaya.Balai RW Banyuurip berlokasi di Kecamatan Sawahan, Surabaya Utara. 
Pemuda karangtaruna Banyuurip kurang lebih berjumlah 50 orang dengan latar belakang dan status yang berbeda-beda, ada yang sudah bekerja, kuliah, berbisnis, dan lain sebagainya. Namun melihat dari keadaan tersebut hanya sedikit dari mereka yang mempunyai bisnis atau usaha sendiri. Padahal jika dilihat para pemuda karangtaruna Banyuurip Surabaya mempunyai potensi untuk membuka bisnis karena banyak dari mereka mempunyai beberapa ide-ide kreatif.

Pada era digital saat ini para pemuda mempunyai potensi besar untuk menjadi entrepreneur ataupun creativepreneur dikarenakan semakin dimudahkan dengan kecanggihan teknologi. Mengembangkan ide-ide krreatif dan menjadi pelaku usaha kreatif akan membuka berbagai peluang besar bagi kemajuan ekonomi di walayah mereka sendiri. Disisi lain persepsi menjadi seorang wirausaha yang kreatif (creativepreneur) ataupun karyawan saja merupakan pilihan yang belum begitu diminati oleh banyak kalangan para pemuda Banyuurip Surabaya, mereka lebih memilih bekerja menjadi karyawan daripada menjadi seorangentrepreneur atau creativepreneur.

Menurut Thomas W. Zimmerer (2008) entrepreneurship (kewirausahaan) merupakan penerapan dari kreativitas dan inovasi dalam memecahkan permasalahan dan sebagai bentuk upaya untuk memanfaatkan peluang yang terjadi. Menurut Andrew J. Dubrin (2008) entrepreneur adalah seseorang yang membangun dan menjalankan sebuah usaha yang inovatif. Berdasarkan hasil pandangan para ahli dapat disimpulkan bahwa entrepreneurship merupakan kemampuan seseorang dalam berfikir kreatif dan berperilaku inovatif yang menjadi dasar, sumber daya, tenaga penggerak, tujuan siasat, kiat dan proses dalam menghadapi tantangan yang terjadi (Apidana, 2012)

Menurut McGrath \& MacMilan (2000) mengatakan adanya istilah entreprurial mindset merupakan suatu hal yang menjadi sangat penting dalam membangun dan membentuk seorang wirausaha. Adanya niat dan motivasi menjadi faktor yang berhubungan dengan pembentukan mindset wirausaha. Dalam teori planned behavior (Fishbein \& Ajzen, 1985 dalam Tjahjono \& Ardi, 2008) diyakini bahwa faktor-faktor seperti sikap, norma subyektif akan membentuk niat seseorang dan selanjutnya secara langsung akan berpengaruh pada perilaku. Oleh karena itu sebuah pemahaman mengenai niat seseorang dalam berwirausaha (entrepreneurial intention) dapat menunjukkan kecendrungan seseorang untuk mendirikan usaha secara nyata (Jenkins \& Johnson, 1997)

Creativepreneurship merupakan salah satu betuk dari wirausaha yang mengedepankan melalui ide-ide kreatif yang dihasilkan. Creativepreneur itu sendiri merupakan pelaku usaha kreatif berdasarkan ide-ide baru yang kreatif dan inovatif. Pada era saat ini menjadi creativepreneur merupakan pilihan alternatif yang paling banyak diminati oleh para anak muda dalam membuka bisnis. Creativepreneur seringkali menghasilkan gagasan baru yang out of the box dimana produknya menjadi hal yang digemari masyarakat. Menjadi seorang pengusaha yang sukses membutuhkan waktu yang tidak instan. Sehingga beberapa orang memilih untuk tidak ingin mengambil risiko dengan berbisnis, (Riyan Sisiawan: 2016)

Peran pemuda sangatlah penting untuk kemajuan maupun pengembangan kewirausahaan dan ekonomi pada masyarakat. Karena pemuda merupakan agent of change yang harusnya mampu memberikan perubahan besar ke arah yang lebih baik. Dan apabila seorang pemuda banyak yang berkeinginan untuk menjadi seorang wirausaha, maka mereka sudah meningkatkan pendapatan di masyarakat dan menjadikan ekonomi pada masyarakat tersebut menjadi produktif. Dengan berbagai pengembangan pemuda karangtaruna Banyuurip diarahkan untuk menjadi seorang creativepreneur yang menjadi salah satu alternatif dalam berbisnis dengan ide-ide kreatif di era sekarang. Hal ini guna bisa memberikan solusi bagi masyarakat dan juga menjadi perubahan baru untuk generasi selanjutnya. Bagi seorang Creativepreneur dalam menjalankan bisnisnya perlu adanya motivasi dengan prinsip kreatif, dan bergabung dengan kelompok yang berbasis digital sehingga dapat memberikan pengaruh yang baik dalam bisnis (Bintang Narpati: 2018). Berdasarkan hal-hal tersebut, Peserta membutuhkan pemahaman lebih dalam mengenai creativepreneur. Bagaimana cara untuk menciptakan jiwa creativepreneur pada bagi karangtaruna Banyuurip, Surabaya. Pengabdian masyarakat yang akan dilakukan berfokus mengenai sikap creativepreneur dengan tujuan untuk menumbuhkan jiwa wirausaha kreatif sejak muda dan supaya peserta bisa membuka bisnis melalui ide-ide keatif yang dihasilkan. 
Berdasarkan analisis situasi yang telah dipaparkan diatas, dapat disimpulkan beberapa permasalah mitra. Permasalahan tersebut adalah sebagai berikut:

1. Kurangnya pemahaman tentang Kewirausahaan dan pentingnya mempunyai jiwa wirausaha kreatif (Creativepreneur)bagi para karangtaruna Banyuurip, Surabaya

2. Kurangnya motivasi dalam berwirausaha, akan tetapi para pemuda berkeinginan untuk membuka usaha kreatif sesuai passion mereka

\section{METODE PELAKSANAAN}

Untuk merealisasikan program ini maka upaya yang dilaksanakan ada 7 tahap mulai dari persiapan sampai tahap pelaksanaan program yaitu antara lain:

1. Mengidentifikasi permasalahan dan kebutuhan mitra

2. Pembentukan Tim: Pembentukan tim disesuaikan dengan jenis kepakaran untuk menyelesaikan permasalahan mitra

3. Pembuatan proposal untuk menawarkan solusi permasalahan dan anggaran dana dalam pelaksanaan kegiatan pengabdian masyarakat

4. Perencanaan pelaksanaan program secara konseptual, operasional dan disesuaikan dengan job desc nya masing-masing anatara Tim dan Mitra.

5. Persiapan bahan Pengabdian Masyarakat: Pembuatan materi kegiatan

6. Sosialisasi mengenai usaha ekonomi kreatif (creativepreneur)

7. Penyusunan laporan dilakukan sebagai bentuk pertanggung jawaban atas pelaksanaan program untuk kemudian di publikasikan.

\section{HASIL KEGIATAN}

Hasil dari proses pengabdian masyarakat yaitu, dalam pelaksanaan program kegiatan meliputi:

1. Sosialisasi

Program pengabdian masyarakat dilaksanakan dalam bentuk sosialisai kepada mitra karangtaruna Banyu urip Surabaya.Sosialisasi tersebut berupa pemaparan materi kepada para Karangtaruna Banyuurip Surabaya terkait menumbuhkan jiwa kewirausahaan kreatif(creativepreneur). Materi yang sudah disampaikan diharapkan dapat memberikan peningkatan pengetahuan dan pemahaman supaya bisa di terapkan apabila akan membuka/merintis sebuah usaha.

2. Diskusi

Setelah materi selesai di sampiakan, dilanjutkan sesi diskusi dengan tanya jawab antara peserta dengan pemateri. Diskusi dilakukan supaya peserta lebih memahami tentang materi yang sudah disampaikan. Melalui diskusi, sosialisai tidak hanya sekedar memberikan materi saja akan tetapi dapat sharing pengalaman maupun permasalahan yang sedang dihadapi oleh mitra.

Pada pasca kegiatan dilakukan evaluasi. Evaluasi pada pelaksanaan kegiatan Pengabdian Kepada Masyarakat untuk kegiatan selanjutnya adalah sebagai berikut:

a. Kegiatan Pengabdian Kepada Masyarakat yang diadakan oleh Fakultas Ekonomi dan Bisnis ini berjalan dengan baik dan sudah sesuai dengan rencana awal.

b. Memberikan pemahaman kepada para pemuda karangtaruna Banyuurip Surabaya mengenai keiwrausahaan ekonomi kreatif (creativepreeur)

c. Dengan diadakannya kegiatan pengabdian kepada masyarakat ini agar supaya bisa memotivasi dan bisa menumbuhkan jiwa wirausaha kreatif bagi para pemuda karang taruna Banyu Urip Surabaya

d. Untuk kegiatan Pengabdian Kepada Masyarakat selanjutnya disarankan supaya tidak berhenti pada memberikan pemaparan materi saja, akan tetapi dengan membina atau melakukan pelatihan agar suapaya peserta lebih termotivasi untuk menjadi wirausaha sejak usia muda.

e. Memberikan materi dan sekaligus mengadakan pelatihan mengenai bisnis 

berikut:

Sedangkan Luaran yang ingin di capai pada kegiatan pengabdian masyarakat adalah sebagai

a. $85 \%$ peserta memahami mengenai ekonomi kreatif dan peluang bisnis di era sekarang

b. $60 \%$ peserta berkeinginan untuk membuka bisnis baru melalui ide-ide kreatif sesuai keahlian mereka

c. $50 \%$ peserta termotivasi untuk mengembangkan bisnis yang telah mereka jalankan dengan memanfaatkan teknologi digital.

\section{DISKUSI}

Berdasarkan Berdasarkan hasil dari kegiatan pengabdian kepada masyarakat mengenai bagaimana cara membangun jiwa wirausaha kreatif (creativepreneur) kepada para pemuda karang taruna Banyu Urip, Surabaya yang dilaksanakan pada tanggal 02 Agustus 2020 ini berjalan dengan baik dan lancar. Para pemateri memberikan arahan dan sosialisasi mengenai kewirausahaan dan memotivasi para masyarakat Banyu Urip untuk terus mengembangkan usaha mereka. Dengan berbagai pengembangan, pemuda karangtaruna Banyuurip diarahkan untuk menjadi seorang creativepreneur yang menjadi salah satu alternatif dalam berbisnis dengan ide-ide kreatif di era sekarang. Hal ini guna bisa memberikan solusi bagi masyarakat dan juga menjadi perubahan baru untuk generasi selanjutnya.

Kegiatan pengabdian masyarakat yang dilakukan oleh Fakultas Ekonomi dan Bisnis ini di sambut baik oleh peserta dan mereka juga meminta supaya kegiatan pengabdian masyarakat ini didakan secara berkelanjutan dengan melalui pelatihan sehingga para peserta dapat merasakan manfaatnya

Rencana tindak lanjut berikutnya dari kegiatan pengabdian masyarakat ini adalah bimbingan yang dilakukan dengan cara mengadakan pelatihan ide bisnis secara langsung dan berkala. Hal ini dimaksudkan agar masyarakat dapat belajar menjadi wirausaha mulai dari awal dan belajar secara bertahap. Selain itu, bagi masyarakat yang telah mempunyai usaha bisnis agar dapat mengembangkan bisnisnya menjadi lebih maju dengan memanfaatkan teknologi digital saat ini. Setelah adanya pelatihan, akan diadakan pengawasan dan konsultasi mengenai permasalahan ataupun kemajuan dari bisnis yang telah dijalankan. Hal ini dilakukan untuk memberikan wawasan dan juga melihat perkembangan seputar usaha kreatif yang sudah berjalan secara bertahap agar nantinya dapat diambil pelajaran untuk kedepannya. Selain itu, hal ini bisa membantu untuk mencapai keberhasilan dari kegiatan pengabdian masyarakat dan bisa menjadi evaluasi untuk mengadakan kembali kegiatan pengabdian masyarakat yang bertema seputar kewirausahaan ataupun cara mmembangun jiwa wirausaha kreatif (creativepreneur) pada masyarakat.

Kegiatan pengabdian kepada masyarakat ini diusahakan untuk diadakan setiap tahun, agar banyak masyarakat yang termotivasi dalam menciptakan ide-ide usaha kreatif dan berkeinginan untuk menjadi seorang entrepreneur yang sukses, melihat semakin berkembangnya era digital saat ini dan banyak entrepreneur baru yang membantu jalannnya perekonomian masyarakat dan juga Negara.

\section{KESIMPULAN}

Berdasarkan kegiatan yang telah dilaksanakan oleh tim pengabdian kepada masyarakat yang dilakukan kepada para pemuda karang taruna Banyu urip, Surabaya dapat disimpulkan bahwa pertama, kegiatan pengabdian kepada masyarakat yang mempunyai tema mengenai cara membangun jiwa wirausaha kreatif (creativpreneur) bagi para pemuda karang taruna Banyu Urip, Surabaya berjalan dengan baik dan sesuai dengan target. Kedua, kegiatan pengabdian kepada masyarakat ini berisi tentang pemapamaran materi oleh tim pengabdian masyarakat dalan dilanjutkan tanya jawab dan diskusi oleh peserta kepada pemateri, sehingga tidak hanya berbagi ilmu saja akan tetapi juga berbagi pengalaman mengenai permasalahan-permasalahan dan informasi menarik seputar wirausaha kreatif di era digital saat ini. 
Ketiga, dengan adanya kegiatan pengabdian masyarakat ini para peserta berantusias dan tertarik untuk membuka ide bisnis baru dengan menyesuaikan passion yang dimiliki dan berharap agar kegiatan pengabdian masyarakat ini bisa ditindaklanjuti melalui pelatihan mengenai kewirausahaan. berikut:

Adapun saran yang dapat disampaikan untuk peningkatan kegiatan selanjutnya adalah sebagai

1. Kegiatan pengabdian kepada masyarakat ini perlu diadakan lagi secara bertahap guna untuk menindaklanjuti kegiatan ini supaya tidak hanya sampai pada pemahaman materi saja akan tetapi diadakan dengan pelatihan dan pembimbingan mengenai kewirausahaan setiap tahun.

2. Kegiatan pengabdian kepada masyarakat ini untuk kedepannya bisa melibatkan banyak peserta lagi dari kalangan masyarakat dan anak muda agar mereka termotivasi untuk lebih produktif dalam meciptakan usaha bisnis baru dan melihat peluang usaha saat ini.

\section{PENGAKUAN}

Alhamdulillah, puji syukur kami panjatkan kehadirat Allah SWT atas Karunia-Nya, penyusunan laporan kegiatan pengabdian masyarakat dengan judul "Cara Meningkatkan Sikap dan Karkteristik Kepemimpinan (Leadership) dalam Berorganisasi Bagi Para Pemuda Karang Taruna Banyu Urip, Surabaya" ini dapat terselesaikan. Laporan kegiatan pengabdian masyarakat ini berisikan mengenai hasil kegiatan sosialisasi dosen dan mahasiswa mengenai sikap kepemimpinan bagi para pemuda karang taruna Banyu Urip, Surabaya. Kegiatan ini dilakukan dengan tujuan meningkatkan sikap dan karakteristik kepemimpinan dalam berorganisasi bagi para pemuda Banyu Urip, Surabaya. Dengan terselesaikannya laporan kegiatan pengabdian masyarakat ini, perkenankan saya mengucapkan terima kasih yang sebesar-besarnya kepada:

1. Prof. Dr. Ir. Achmad Jazidie, M.Eng selaku Rektor Universitas Nahdlatul Ulama Surabaya.

2. Dr. Istas Pratomo, S.T., M.T selaku Ketua Lembaga Penelitian dan Pengabdian Masyarakat Universitas Nahdlatul Ulama Surabaya.

3. Dr. Mohamad Yusak Anshori, M.M Dekan Fakultas Ekonomi dan Bisnis Universitas Nahdlatul Ulama Surabaya.

4. Riyan Sisiawan Putra, S.E., M.SM selaku Ketua Program Studi S1 Manajemen Universitas Nahdltul Ulama Surabaya.

5. Moch Imam Suyuti selaku Ketua RT.02 Banyu Urip Jaya dan para pemuda karang taruna Banyu Urip, Surabaya atas bantuannya selama kegiatan berlangsung.

6. Para anggota pelaksana pengabdian masyarakat yang terlibat dalam pelaksanaan pengabdian masyarakat.

Demikian, semoga laporan ini dapat memberi manfaat bagi diri saya sendiri, dan untuk pengembangan penelitian bidang kesehatan masyarakat maupun semua pihak yang menggunakan.

\section{DAFTAR PUSTAKA}

Apidana, Gregrorius Fajar. Faktor-Faktor Penghambat, Pendukung, Penentu Kegagalan Dan Keberhasilan Entrepreneurship Dalam Dunia Konstruksi. (2012). S2 Thesis.Universitas Atmajaya Jogjakarta.

McGrath, R. G. \& MacMillan, I. C. The entrepreneurial mindset : strategis for countinuosly creating opportunity in an age of uncertainty. Boston, Mass.: Harvard Business School Press (2000)

Narpati Bintang dan Kardinah. (2018) Creativepreneur Menjamin Kesejahteraan di Masa Depan?. Journal Ikra-Ith Ekonomika 1 (2), 139-145

Jenkins, M. \& Johnson, G. Entrepreneurial Intentions and Outcomes: A Comparative Causal Mapping Study. Journal Management Studies (1997), 34, 895-920.

Putra, R. S.(2016). Kewirausahaan: Mengubah Pola Pikir Karyawan Menjadi Pola Pikir Pengusaha. 
Surabaya:PPM

Wijoyo, H., \& Haudi, H. (2021, January). PENYULUHAN TEKNIK PEMASARAN KERUPUK RASA JENGKOL "DONG DONG SNACK" PEKANBARU. In PROSIDING SENANTIAS: Seminar Nasional Hasil Penelitian dan Pengabdian kepada Masyarakat (Vol. 1, No. 1, pp. 643-650).

Wijoyo, H. (2020). Socialization Of The Accreditation Asessment System (SISPENA) Of The National Accreditation Board For Early Childhood Education (PAUD) And Non Formal Education (PNF) In Bengkalis, Riau Province. Jurnal Humanities Pengabdian Kepada Masyarakat, 1(1), 103-111.

Wijoyo, H., Haudi, H., Ariyanto, A., Sunarsi, D., \& Akbar, M. F. (2020). Pelatihan Pembuatan Konten Digital Marketing Dalam Meningkatkan Kompetensi Mahasiswa (Pengabdian Kepada Masyarakat Kerjasama Antar Kampus). IKRA-ITH ABDIMAS, 3(3), 169-175.

Wijoyo, H. (2020). Sosialiasi Sistem Penilaian Akreditasi (SisPenA) Badan Akreditasi Nasional Pendidikan Anak Usia Dini (PAUD) dan Pendidikan Non Formal (PNF) di Kecamatan Bantan, Kabupaten Bengkalis, Propinsi Riau. ARBITRASE: Journal of Economics and Accounting, 1(1), 7-10. 